\title{
Desenvolvendo Competências de Trabalho para o Século 21 por meio de Jogos Eletrônicos: um relato de experiência
}

\author{
Leonardo Cordeiro de Araújo ${ }^{1}$, Renata Cardillo Homem de Mello ${ }^{2}$
}

${ }^{1}$ Escola Técnica Estadual José Humberto de Moura Cavalcanti

Rodovia PE-90, S/N, Km 24, Coqueiros, Limoeiro - PE - Brasil

${ }^{2}$ Universidade Metodista de São Paulo

Rua Alfeu Tavares, Rudge Ramos, São Bernardo do Campo, São Paulo - SP - Brasil

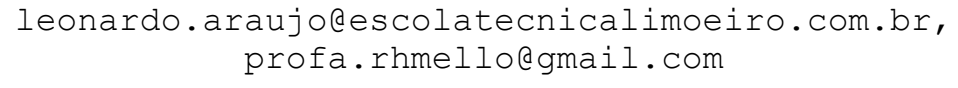

\begin{abstract}
This article reports the effort of a school practice with the use of electronic games of simulation and strategy. The aim was present the possibility of working the development of interpersonal and intrapersonal skills required for the professional of the 21st century. The application occurred with 76 students from a state public school. More than $65 \%$ of these students were able to satisfactorily assimilate the theoretical concepts in a practical way.
\end{abstract}

Resumo. Este artigo relata a aplicação de uma prática escolar com a utilização de jogos eletrônicos de simulação e estratégia. O objetivo é apresentar a possibilidade de se trabalhar o desenvolvimento de competências interpessoais e intrapessoais exigidas para o profissional do século 21. A aplicação ocorreu com 76 estudantes de nível médio/técnico em uma escola pública estadual. Mais de $65 \%$ destes estudantes conseguiram assimilar, de forma satisfatória, os conceitos teóricos de maneira prática.

\section{Introdução}

Muito se tem discutido a respeito dos novos desafios enfrentados quanto em se tornar um profissional no acirrado mercado de trabalho no século 21. Podemos dizer que, hoje, o grande desafio, no que se refere ao trabalho, está na falta de profissionais qualificados em setores específicos e, ainda mais agravante, na ausência de profissionais que, mesmo tecnicamente qualificados, ainda não conseguiram alcançar competências necessárias ao desenvolvimento interpessoal e intrapessoal [Rocha Sobrinho e Porto 2012]. No contexto educacional, para se trabalhar tais competências ausentes em muitos profissionais, novas formas de utilização das tecnologias de informação e comunicação (TICs) têm se destacado, por exemplo, com a utilização de jogos eletrônicos para fins de apoio à aprendizagem [Hochsprung e Cruz 2017], sendo uma das principais fontes de sucesso à motivação [Brandão et al. 2018].

Com essa contextualização, este trabalho tem como objetivo apresentar a possibilidade de se trabalhar com jogos eletrônicos de simulação e estratégia o desenvolvimento de competências exigidas para o profissional do século 21 , através de um relato de experiência. 
VIII Congresso Brasileiro de Informática na Educação (CBIE 2019)

Anais do XXV Workshop de Informática na Escola (WIE 2019)

\section{Competências de Trabalho no Século 21 e o uso de Jogos Eletrônicos como Ferramentas de apoio à Aprendizagem}

Três trabalhos relevantes foram identificados na literatura relacionados ao tema citado: o ensaio sobre competências do século 21, de Soffner [Soffner 2014], que trata da importância da discussão, compreensão e aplicação das novas competências na vida dos educandos no âmbito escolar; o artigo de Roldão [Roldão 2009], que discute a importância da adoção das competências no currículo escolar para uma aprendizagem significativa e o artigo de Sá e Paixão [Sá e Paixão 2013], que faz um grande apanhado e discussão em cima de projetos/pesquisas da comunidade europeia, mas que pode ser generalizada mundialmente, relacionados à identificação e definição das competências que todos os cidadãos devem possuir no século 21.

Uma das formas de se utilizar as TICs no processo educacional é através da adoção de jogos eletrônicos no processo de ensino e de aprendizagem. A própria BNCC, em sua $5^{\mathrm{a}}$ competência geral, trata da necessidade da adoção das TICs de forma crítica, significativa, reflexiva e ética para o exercício do protagonismo e autoria na vida pessoal e coletiva [Brasil 2018]. Logo, os jogos eletrônicos são classificados em diversas categorias, entre elas simuladores e estratégia [Sato e Cardoso 2008]. Tais classificações, embora distintas, podem coexistir em suas aplicações, sendo grandes aliados da educação, podendo ser utilizados para desenvolver diversos tipos de habilidades [Baladez 2009].

\section{Aplicação do Trabalho}

Resolveu-se aplicar uma atividade prática, dentro de uma sequência didática dividida em três momentos: coleta de dados, aplicação e avaliação. Participaram 76 estudantes adolescentes entre duas turmas do $1^{\circ}$ ano do ensino médio e técnico do curso de Informática para Internet, na Escola Técnica Estadual José Humberto de Moura Cavalcanti, escola pública na cidade de Limoeiro, no estado de Pernambuco. A atividade foi executada na disciplina de Projeto Integrador, disciplina esta responsável por inserir conteúdos diversos relacionados à prática das tecnologias de informação na vida profissional dos estudantes, através de pesquisas e projetos.

\subsection{Primeiro momento}

No primeiro momento, em sala de aula, os 76 estudantes presentes foram orientados a pesquisarem na internet sobre as competências de trabalho exigidas para o século 21 . Em seguida eles discutiram o que encontraram sobre o tema e realizaram um apanhado geral. Depois, as competências identificadas foram analisadas e chegou-se à escolha de 15 delas, sendo essas encontradas em um artigo da revista digital ComputerWorld, disponível em: $<$ http://gg.gg/artigo-comp $>$, o qual foi identificado pelas duas turmas. As competências escolhidas pelas turmas foram confrontadas, pelo professor, com o material apresentado nos três trabalhos da Seção 2. As 15 competências escolhidas foram: Solução complexa de problemas, Pensamento crítico, Criatividade, Gestão de pessoas, Coordenação com os outros, Inteligência emocional, Julgamento e tomada de decisão, Orientação para o serviço, Negociação, Flexibilidade cognitiva, Adaptabilidade, Iniciativa e empreendedorismo, Inteligência social, Alfabetismo em mídia e programação e Colaboração virtual.

Em seguida, as 15 competências de trabalho selecionadas foram distribuídas entre grupos, através de sorteio. Cada grupo ficou com a responsabilidade de pesquisar mais 
VIII Congresso Brasileiro de Informática na Educação (CBIE 2019)

Anais do XXV Workshop de Informática na Escola (WIE 2019)

sobre a competência e criar uma pequena peça teatral, utilizando o conceito de storytelling, abordando a vivência das competências por grupo na possível realidade de mercado. A peça foi apresentada em 5 minutos por cada grupo na própria sala de aula, encerrando o primeiro momento da aplicação deste trabalho.

\subsection{Segundo momento}

No segundo momento em sala de aula, foi apresentado aos estudantes das turmas o jogo de computador SimCity 4, com informações disponíveis em: $<$ http://gg.gg/jogo-sc4>. O objetivo era estimular os estudantes a perceberem alguma competência de trabalho abordada até o momento. Depois, eles escolheram jogos de simulação e estratégia, em seus grupos, utilizando smartphones, objetivando identificar quantas competências, das 15, fossem possíveis durante o jogo e se era possível desenvolver as competências identificadas. Eles tiveram uma semana para discutirem em grupo e produzir um cartaz contendo informações sobre o jogo escolhido e as competências identificadas durante o jogo.

Foram escolhidos 15 jogos, nenhum se repetindo entre as equipes, e todos na plataforma smartphone, Android e iOS, sendo eles: Turma A (Ataque Zumbi, Block Strike, City Island 5, City Mania, Clash of Clans, Clash Royale e Dragon City); Turma B (Gartic, League of Legends, Little Big City, Little Big City 2, SimCity Buildt, Slices, The Sims Free Play e Township).

\subsection{Terceiro momento}

No terceiro e último momento, os estudantes foram direcionados a responderem individualmente a um questionário disponível em: <http://gg.gg/comp-form>, cujos resultados estão apresentados na Seção 4. Esse questionário teve como objetivos identificar quais e quantas competências foram identificadas pelos estudantes, as suas observações acerca da aplicação no jogo escolhido, além da assimilação do conteúdo apresentado sobre as competências por meio de 5 perguntas com situações-problema.

\section{Resultados e Discussões}

A produção dos cartazes resultou em uma exposição na escola, objetivando outros estudantes da escola a perceberem que, mesmo em momentos de diversão utilizando jogos eletrônicos, é possível identificar e trabalhar características úteis a serem aplicadas no meio profissional. A Figura 1 apresenta tanto o momento do teatro por uma das equipes quanto alguns dos cartazes expostos na escola.
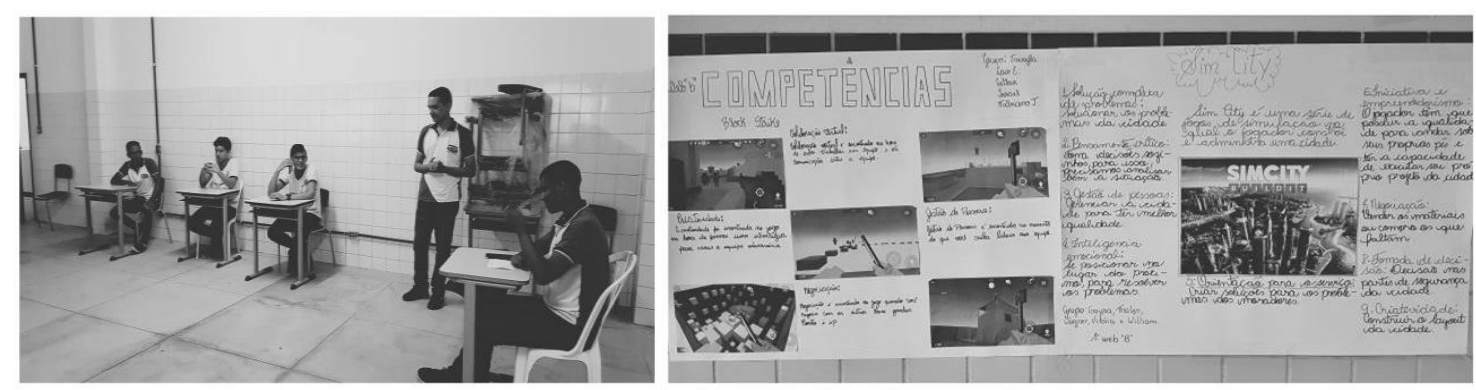

Figura 1. Apresentação teatral (esquerda) e alguns cartazes expostos (direita)

O momento avaliativo, através do questionário respondido pelos estudantes, apresentou uma série de resultados. Um deles, conforme a Figura 2, apresenta o resultado, em gráfico, acerca das competências escolhidas mais identificadas pelos estudantes. 
VIII Congresso Brasileiro de Informática na Educação (CBIE 2019)

Anais do XXV Workshop de Informática na Escola (WIE 2019)

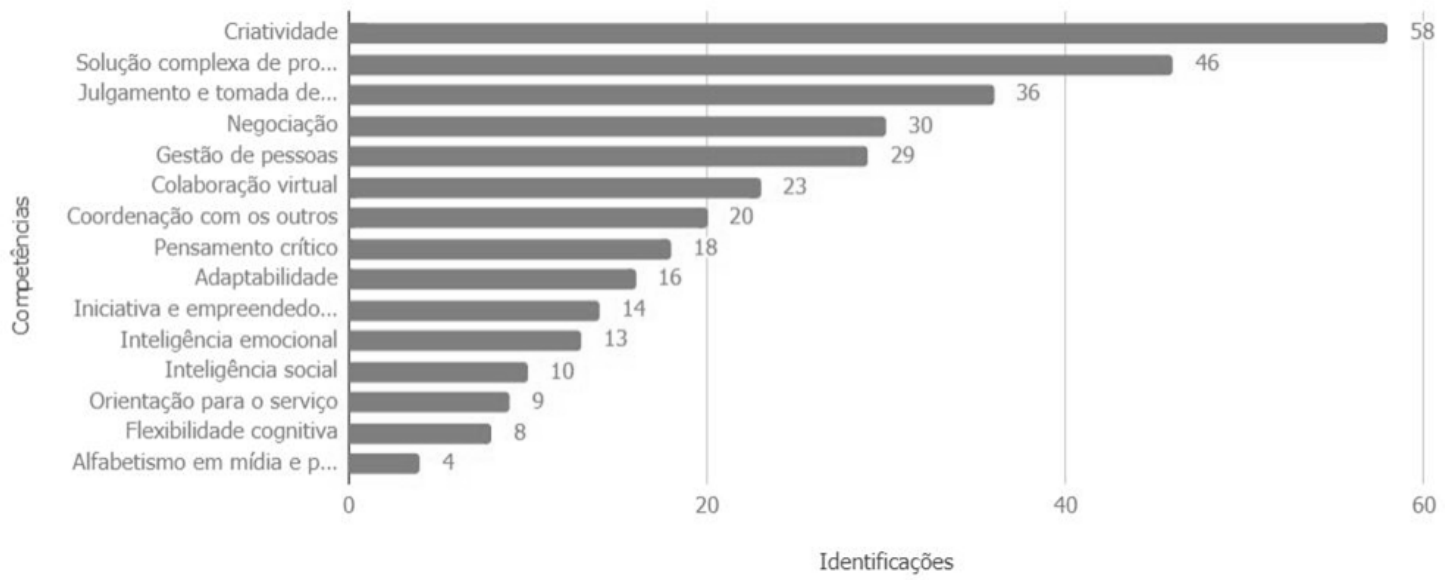

Figura 2. Quantidade de competências identificadas nos jogos pelos estudantes

Podemos destacar que as competências Criatividade, Solução complexa de problemas e Julgamento e tomada de decisões foram as mais identificadas nos jogos. Observa-se ainda que todas as 15 competências foram identificadas pelos estudantes nos jogos selecionados. Outro resultado mostrou se o uso de jogos eletrônicos de estratégia e simulação atendeu a expectativa de desenvolver competências de trabalho, sendo as respostas "Sim", "Um pouco" e "Não". Como destaque temos o "Sim" com 80\% das respostas e a ausência do "Não.

Quanto às repostas dissertativas dadas pelos estudantes, coletou-se um total de 76 . Algumas respostas dos estudantes quanto a experiência em identificar competências de trabalho no jogo escolhido estão resumidas a seguir.

Estudante 1: "Tive a oportunidade de identificar diversas competências nesse jogo. Percebi o quanto é difícil administrar tudo de forma coerente e correta, foi uma ótima experiência."

Estudante 2: "No começo foi um pouco difícil não entendia direito, mas depois fui pegando o jeito e identifiquei algumas competências."

Estudante 3: "Tudo está relacionando com o mundo real. Mesmo sendo um jogo, pudemos identificar essas competências."

Sobre as respostas dadas pelos estudantes às perguntas com situações-problema, houve variação na quantidade de acertos de acordo com a pergunta. Das cinco perguntas, três obtiveram acima de $50 \%$ de acertos. Com destaque às duas perguntas que obtiveram menos de $50 \%$ de acertos, a pergunta cuja competência correta seria "Orientação para o serviço", 28 estudantes responderam como sendo a competência "Criatividade". Para a pergunta cuja competência correta seria "Colaboração virtual", 41 responderam "Coordenação com os outros". Sendo assim. em uma média aritmética, chegou-se ao resultado de $66 \%$ dos estudantes que conseguiram assimilar o conteúdo. As demais respostas, assim como o resultado geral da avaliação e os gráficos gerados, podem ser acessados na internet disponível em: <http://gg.gg/comp-respostas $>$.

\section{Conclusões}

Com a aplicação deste trabalho, observou-se que é possível identificar e trabalhar o desenvolvimento das competências intrapessoais e interpessoais estudadas, mesmo fora do mercado. Com a adoção da sequência didática apresentada, os estudantes conseguiram 
VIII Congresso Brasileiro de Informática na Educação (CBIE 2019)

Anais do XXV Workshop de Informática na Escola (WIE 2019)

captar a essência do assunto abordado, aplicando as teorias em situações que exigiram deles a aplicabilidade de várias das competências identificadas. Mesmo com $66 \%$ de assimilação, é possível afirmar que houve êxito com a técnica aplicada. Logo, percebeuse que é factível de se trabalhar com esse tipo de método, incluindo jogos eletrônicos, temas relacionados à prática de mercado de trabalho. Entretanto, é possível outras aplicações com esta temática, ficando como sugestões para trabalhos futuros:

- Aplicar outros estilos de jogos eletrônicos;

- Aplicar novas situações-problema e outras formas de avaliação como verificação de aprendizagem do estudante;

- Desenvolver, com os estudantes, jogos nos estilos avaliados, adotando as competências trabalhadas.

- Trabalhar, individualmente, cada uma das competências.

\section{Agradecimentos}

Os autores agradecem aos colegas docentes e estudantes participantes da Escola Técnica, especialmente à professora Mavja Christhiane S. M. V. da Silva e ao professor Antônio José de Lima Neto.

\section{Referências}

Baladez, F. (2009) "O passado, o presente e o futuro dos simuladores". In Fasci-Tech, v.1, n.1.

Brandão, L. O.; Félix, I. M.; Brandão, A. A. F.; Pereira, P. A. (2018). "Ensinando com jogos ou jogando com o ensino: a visão da comunidade brasileira de Informática na Educação sobre jogos no ensino de matemática". In Anais do XXIX SBIE, p. 742.

Brasil, Ministério da Educação. (2018) "Base Nacional Comum Curricular", http://basenacionalcomum.mec.gov.br/images/BNCC_EI_EF_110518_versaofinal_si te.pdf, Junho.

European Commission (2004). "Key Competences for Lifelong Learning: a European Reference Framework Directorate-General for Education and Culture", http://europa.eu.int/comm/education/policies/2010/doc/basicframe.pdf, Junho.

Hochsprung, J. e Cruz, D. M. (2017) "Jogos digitias/eletrônicos em sala de aula: uma revisão sistemática". In Proceedings os SBGames.

Rocha Sobrinho, F. e Porto, J. B. (2012) "Bem-estar no trabalho: um estudo sobre suas relações com clima social, coping e variáveis demográficas". In Journal of Contemporany Administration, v.16, n.2.

Roldão, M. C. (2009) "O lugar das competências no currículo - ou o currículo enquanto lugar das competências". In EMP, v.11, n.3.

Sá, P. e Paixão, F. (2013) "Contributos para a clarificação do conceito de competência numa perspectiva integrada e sistêmica". In Rev. Port. de Educação, vol.26, n.1, Braga.

Soffner, R. K. (2014) "Competências do século 21". In Debate em Educação, v.4, n,1. 